\title{
Verification of the selectivity of a liquid chromatography method for determination of stilbenes and flavonols in red wines by mass spectrometry
}

\author{
Letícia F. da Silva ${ }^{1,2}$ - Celito C. Guerra ${ }^{1}$ Alana Foresti ${ }^{1,3} \cdot$ Ana M. Bergold $^{2}$
}

Received: 21 March 2016/Accepted: 19 June 2016

(C) Institute of Chemistry, Slovak Academy of Sciences 2016

\begin{abstract}
Quantification of bioactive phenols, like stilbenes and flavonols $(\mathrm{SaF})$, has been conducted to evaluate the nutraceutical potential of red wines. However, there is still a lack of full validated, fast and accessible liquid chromatography methods offering high selectivity and a simple procedure. We present here the use of a high-resolution mass spectrometer to evaluate the selectivity of a feasible and traditional liquid chromatography technique (HPLC$\mathrm{DAD})$ to analyze markers of aglycone $\mathrm{SaF}$ in red wines. The SaF compounds were tested: trans-resveratrol, trans- $\varepsilon^{-}$ viniferin, quercetin, myricetin, and kaempferol, as well as trans-cinnamic acid, one of their precursors. System suitability and validation tests were employed for the selected conditions (octylsilane column, methanol mobile phase, and gradient elution). The validation process ensured the HPLC-DAD method was selective, linear, sensitive, precise, accurate and robust. The method was then applied to red wine samples from the Campanha Gaúcha region, Southern Brazil. The real samples contained different $\mathrm{SaF}$ levels, showing that the method is applicable to routine use. Furthermore, this was the first $\mathrm{SaF}$ characterization of red wines from the Campanha Gaúcha, contributing to regional and product development.
\end{abstract}

Letícia F. da Silva

leticiaflores.1f@outlook.com

1 LACEM-Laboratório de Cromatografia e Espectrometria de Massas, Embrapa Uva e Vinho, Rua Livramento, 515, Bento Gonçalves, RS 95700-000, Brazil

2 Laboratório de Química Farmacêutica, Faculdade de Farmácia, Universidade Federal do Rio Grande do Sul, Av. Ipiranga, 2752, Porto Alegre, RS 90610-000, Brazil

3 Tecnologia em Viticultura e Enologia, Instituto Federal do Rio Grande do Sul, Av. Osvaldo Aranha, 540, Bento Gonçalves, RS 95700-000, Brazil
Keywords Bioactive phenols $\cdot$ Red wine $\cdot$ Liquid chromatography $\cdot$ Mass spectrometry $\cdot$ Validation

\section{Abbreviations}

\section{Symbols}

$t_{\mathrm{R}} \quad$ Retention time (min)

$\mathrm{V} / \mathrm{V} \quad$ Volume/volume (\%)

$R_{\mathrm{S}} \quad$ Resolution

TF Asymmetry

$k \quad$ Capacity factor

$N \quad$ Theoretical plates

$r^{2} \quad$ Coefficient of determination

$F_{\text {calc }} \quad$ Calculated Fisher value

$F_{\text {tab }}$ Fisher table value

$n \quad$ Number of repetitions

$p \quad$ Probability

$\mathrm{m} / z \quad$ Mass/charge (Da)

\section{Greek letters}

$\lambda_{\max }$ Maximum ultraviolet absorption wavelength (nm)

\section{Introduction}

Biological studies, dealing with the French Paradox, showed that red wines are associated with increased longevity and the prevention of diseases in moderate consumers (Bidlack and Wang 2006; Renaud and De Lorgeril 1992), and that such responses could be mainly attributed to the wine phenol constituents (Flamini et al. 2013; Khan et al. 2013). The wide variety of phenolic compounds found in wines has as their precursor trans-cinnamic acid. 
They are derived from the secondary metabolism of grapes and may be classified into non-flavonoid and flavonoid groups (Crozier et al. 2006; Ribéreau-Gayon et al. 2006). Among these classes, the bioactive stilbenes and flavonols $(\mathrm{SaF})$ are the focus of the nutritional aspects of grapes and their derived products, which are some of the major sources of such compounds in the human diet (Bidlack and Wang 2006; Malovaná et al. 2001; Monagas et al. 2005; Pereira et al. 2010; Pérez-Magarino et al. 2008; Rodríguez-Delgado et al. 2002; Silva et al. 2011; Tenore et al. 2011; Villiers et al. 2004; Vitrac et al. 2005; Vrhovsek et al. 2012).

Stilbenes are non-flavonoid molecules, such as transresveratrol, trans-piceid and viniferin, whereas flavonols are from the flavonoid class, such as quercetin, kaempferol and myricetin (Crozier et al. 2006; Ribéreau-Gayon et al. 2006). Trans-resveratrol and quercetin, for example, have been extensively evaluated due to their biological activities in the cardiovascular system, brain protection, antioxidative processes, and antitumor and anti-inflammatory actions (Baur et al. 2006; Bidlack and Wang 2006; Flamini et al. 2013; Prior 2006; Tringali 2012). The majority of the grape phenols naturally occur as glycosides, but the wine fermentation processes in acid media usually promote the hydrolysis of the glycoside linkage giving the corresponding aglycone molecules, which are easier to absorb through the gastrointestinal system (Bidlack and Wang 2006; Crespy et al. 1999, 2002; Murota and Terao 2003).

The development of wines containing high levels of $\mathrm{SaF}$ may enhance the health benefits already identified in humans (Cotea et al. 2012). It may be substantially supported by a chemical characterization of the SaF biosynthetic pathways, where some $\mathrm{SaF}$ markers would be detected in higher doses than their common precursors (e.g., trans-cinnamic acid) (Baur et al. 2006; Prior 2006). UPLC (ultra-performance liquid chromatography) coupled to a MS (mass spectrometer) is the most modern technique and, in principle, can create faster and more selective methods than HPLC (high-performance liquid chromatography) coupled to a DAD (diode array detector) (CieleckaPiontek et al. 2013). Indeed, UPLC-MS should be the first choice for SaF quantification in wines. However, UPLCMS is not widely available in food laboratories yet, because of the high costs associated with purchasing, and the need for maintenance and skilled personnel. Therefore, it seems clear that the HPLC-DAD may be a suitable analytical option for several laboratories, since it is still the most widespread LC (liquid chromatography) instrumentation worldwide, mainly in wineries or small research centers, where the funding and resources are sometimes restricted. Some previous publications used HPLC-DAD for $\mathrm{SaF}$ determination in wines (Adrian et al. 2000; Aznar et al. 2011; Cotea et al. 2012; Malovaná et al. 2001; Pereira et al. 2010; Pérez-Magarino et al. 2008; Villiers et al. 2004; Vitrac et al. 2005). A simple direct injection of the samples for analysis of resveratrol and other $\mathrm{SaF}$ has been described in some methods (Adrian et al. 2000; Careri et al. 2004; Castellari et al. 2002; López et al. 2001; Pereira et al. 2010; Revilla and Ryan 2000; Vitrac et al. 2005). Complex sample preparation has been required by other procedures (Baptista et al. 2001; Cotea et al. 2012; Fontana and Bottini 2014; Kerem et al. 2004; Lima et al. 1999; Malovaná et al. 2001; Paulo et al. 2011; Pérez-Magarino et al. 2008; Villiers et al. 2004), but they may introduce analytical errors, be expensive, cause environmental pollution due to chemical waste and be time-consuming.

The evaluation of the selectivity for each chromatographic peak is another important aspect, since it is a crucial validation requirement for such methods (ANVISA 2003; FDA, US Food and Drug Administration 2001; González et al. 2014; ISO International Organisation for Standardisation 2005). Concerning SaF determination in wines, a full exploration of selectivity data is indispensable because the compounds have similar chemical characteristics among themselves and with other organic compounds in the matrix, such as the high levels of red wine pigments (anthocyanins, a positively charged flavonoid class). Interfering compounds may exhibit coelution and, consequently, lead to overestimation of the content, or non-selective detection of, the analytes (González et al. 2014). The DAD detector and, mainly, high-resolution mass spectrometers (e.g., a hybrid quadrupole time-of-flight, or QTOF, instrument) may be able to provide more data through software tools, such as providing the purity index of the chromatographic peaks (ANVISA 2003; FDA US Food and Drug Administration 2001; Kazakevich and Lobrutto 2007). Despite this, selectivity has not been extensively investigated for these analyses when DAD is the detector (Adrian et al. 2000; Aznar et al. 2011; Castellari et al. 2002; Cotea et al. 2012; Gómez-Alonso et al. 2007; Kerem et al. 2004; Lima et al. 1999; López et al. 2001; Malovaná et al. 2001; Pereira et al. 2010; Pérez-Magarino et al. 2008; Rastija et al. 2009; Revilla and Ryan 2000; Villiers et al. 2004; Vitrac et al. 2005). A few selective and validated HPLC-DAD methods were found (Baptista et al. 2001; Careri et al. 2004; Fontana and Bottini 2014), but they did not focus on SaF markers. In the literature, no HPLC-DAD method that combines a short analysis time (below $30 \mathrm{~min}$ ), simple sample preparation, and full validation with high selectivity has so far been reported. Conditions like these are useful to combine timereduction with good laboratory practices (Lorrain et al. 2013). Thus, this study aimed to employ QTOF to check the selectivity of a feasible HPLC-DAD method for chemical characterization of the SaF biosynthetic pathways (trans-resveratrol, trans- $\varepsilon$-viniferin, quercetin, myricetin, 
kaempferol and trans-cinnamic acid) in red wines, with no sample preparation. A preliminary application of the method in routine analyses of Southern Brazilian red wines is also presented here.

\section{Experimental}

\section{Chemicals and standards}

Methanol, acetonitrile and formic acid were HPLC grade, and were purchased from Sigma-Aldrich (St. Louis, MO, USA). Reagent grade ethanol was obtained from Merck (Darmstadt, Germany). Ultra-pure water (Milli-Q, Millipore, USA) was used to prepare all the solutions. Analytical standards of transcinnamic acid, trans-resveratrol, trans- $\varepsilon$-viniferin, quercetin, kaempferol and myricetin were purchased from SigmaAldrich (St. Louis, MO, USA). Malvidin-3-O-glucoside and $(+)$-catechin were purchased from Extrasynthese (Genay, France). All standards were of at least $94 \%$ purity.

A stock solution was prepared containing $200 \mu \mathrm{g} \mathrm{mL}^{-1}$ of each analyte, whose concentrations were corrected according to respective purities, and was diluted with ethanol 70\% (V/V in water). Fractions of the stock solution were kept protected from light and stored at $4{ }^{\circ} \mathrm{C}$ for a week. The working standard solutions were prepared daily.

\section{Samples of red wines}

Tests were conducted with samples of commercial red wines from the Campanha Gaúcha region, the grapes for which were harvested between January and February 2012. The following wine samples derived from six different varieties of grapes were used: Cabernet Franc, Cabernet Sauvignon, Malbec, Merlot, Tannat, and Tempranillo.

Before analysis, all samples were stored at $20 \pm 2{ }^{\circ} \mathrm{C}$. Samples were filtered through a $0.45 \mu \mathrm{m}$ hydrophilic PVDF (polyvinylidene fluoride) membrane (Millipore, USA), and used without dilution.

\section{Method development}

The method conditions were optimized by testing different solvents (acetonitrile and methanol), column types (octylsilane-C8 and octadecilsylane-C18), column lengths (15 and $25 \mathrm{~cm})$, column packing particle sizes $(2.6$ and $5.0 \mu \mathrm{m})$ and elution gradients. The peaks of the chromatograms were evaluated by $R_{\mathrm{S}}$ (resolution) and TF (asymmetry), following suitability recommendations (Bliesner 2006; FDA US Food and Drug Administration 1994; Kazakevich and Lobrutto 2007; Shabir 2003).

The settings for DAD detector were experimentally established. For this, the $t_{\mathrm{R}}$ (retention time) and $\lambda_{\max }$ (maximum ultraviolet absorption wavelength) were determined for each analyte. Full system suitability was also checked, considering: $k$ (capacity factor), $R_{\mathrm{s}}, \mathrm{TF}$ and $N$ (number of theoretical plates).

\section{HPLC-DAD conditions}

Determinations of $\mathrm{SaF}$ and trans-cinnamic acid were carried out by HPLC-DAD. A Shimadzu system (Kyoto, Japan) equipped with a DAD detector (SPD-M10AVP), two dual piston solvent delivery pumps (LC-10AD), a controller module (UFLC CBM-20A) and CLASS VP software (version 6.12) were used. The column selected was a $\mathrm{C} 8$ (vertical) $150 \times 4.6 \mathrm{~mm}, 5 \mu \mathrm{m}$ particle size, carbon load of $9 \%$, surface area of $450 \mathrm{~m}^{2} \mathrm{~g}^{-1}$ and pore size $10 \mathrm{~nm}$. It was protected with a guard column of $\mathrm{C} 8$ material (Phenomenex). Detection was conducted at 276, $306,322,365,371$ and $374 \mathrm{~nm}$, according to the $\lambda_{\max }$ of each analyte. The injection volume was $20 \mu \mathrm{L}$ and the flow rate was $1 \mathrm{~mL} \mathrm{~min}{ }^{-1}$. Mobile phase A consisted of formic acid and water $(1: 1000, \mathrm{~V} / \mathrm{V})$ and mobile phase $\mathrm{B}$ consisted of methanol, formic acid and water (900:1:100, V/V/V). The linear gradient was: from 30 to $45 \%$ of $\mathrm{B}$ in $7 \mathrm{~min}$, $45 \%$ of B for $7 \mathrm{~min}$, from 45 to $55 \%$ of B in $1 \mathrm{~min}$, from 55 to $65 \%$ of B in $9 \mathrm{~min}$, from 65 to $90 \%$ of B in $1 \mathrm{~min}, 90 \%$ of B for $2 \mathrm{~min}$, from 90 to $30 \%$ of B in $0.5 \mathrm{~min}, 30 \%$ of B for $2.5 \mathrm{~min}$. The total time of analysis was $30 \mathrm{~min}$.

\section{Method validation}

The analytical method described in the "HPLC-DAD conditions" section was validated for its intended use. The performance characteristics defined in the validation guidelines from the Food and Drug Administration (FDA US Food and Drug Administration 2001) and the Brazilian Health Surveillance Agency (ANVISA 2003) were followed.

Selectivity was evaluated by assessing peak purity and $R_{\mathrm{s}}$. Purity was determined using features of the DAD detector managed by the CLASS VP software, as follows: overlay of the spectra at different peak points; calculation of the purity index (from 250 to $600 \mathrm{~nm}$ ); evaluation of the contour graph; and plots of three-dimensional (3D) graphs. Peaks of compounds were considered pure when the purity index was higher than 0.99 .

For a more consistent evaluation of selectivity, an Ultima API Q-TOF instrument (Micromass, Manchester, UK) was used and it was controlled by Masslynx software, version 4.1 (Waters, Milford, United States). The analyses were conducted with ESI (electrospray ionization), in positive mode scanning from $\mathrm{m} / \mathrm{z} 150$ to 1000 . The cone and desolvation nitrogen supply (99.0\% purity) was set at flow rates of 30 and $300 \mathrm{~L} \mathrm{~h}^{-1}$, respectively. The 
instrument operation conditions were: capillary voltage of $2000 \mathrm{~V}$, cone voltage of $100 \mathrm{~V}$, source temperature of $80^{\circ} \mathrm{C}$, desolvation temperature of $150{ }^{\circ} \mathrm{C}$. TOF was set at $9100 \mathrm{~V}$, and detector voltage (MCP) was $1900 \mathrm{~V}$, in $\mathrm{V}$ mode. The $m / z$ data were registered by comparison with malvidin-3-O-glucoside $(\mathrm{m} / \mathrm{z}$ 493.14) and $(+)$-catechin $(\mathrm{m} /$ $z$ 291.09) standards, both of which are common wine constituents.

Linearity was performed by analyzing of three calibration curves on different days. Each solution was injected in triplicate. The stock solution was used to prepare calibration curve solutions at six concentration levels, being all of them diluted in ethanol $70 \%$ (V/V in water) (see "Chemical and standards" section). For cinnamic acid the concentrations were $0.1,1.0,2.5,5.0,7.5$ and $10.0 \mu \mathrm{g} \mathrm{mL}^{-1}$, whereas for the other analytes (trans-resveratrol, trans- $\varepsilon^{-}$ viniferin, quercetin, kaempferol and myricetin) the concentrations were $1.0,5.0, \quad 10.0,20.0,30.0$ and $40.0 \mu \mathrm{g} \mathrm{mL}^{-1}$. Linear regression equations were calculated by the least squares method. The linearity was evaluated by ANOVA.

Sensitivity was assessed by LOD (limit of detection) and LOQ (limit of quantification). They were determined by the noise level of the chromatograms obtained from linearity studies (ANVISA 2003; FDA US Food and Drug Administration 2001).

Precision was determined by an intra-day test (repeatability) and an inter-day test (intermediate precision). Repeatability was conducted by spiking a sample (Cabernet Sauvignon) with three concentration levels of $\mathrm{SaF}$ standards, prepared as six replicates on the same day. Concentrations were: low $\left(\mathrm{L}, 2.5 \mu \mathrm{g} \mathrm{mL}^{-1}\right.$ for cinnamic acid and $10.0 \mu \mathrm{g} \mathrm{mL}^{-1}$ for the $\left.\mathrm{SaF}\right)$, medium (M, $5.0 \mu \mathrm{g} \mathrm{mL}^{-1}$ for cinnamic acid and $20.0 \mu \mathrm{g} \mathrm{mL}^{-1}$ for the $\mathrm{SaF})$ and high $\left(\mathrm{H}, 7.5 \mu \mathrm{g} \mathrm{mL}{ }^{-1}\right.$ for cinnamic acid and $30.0 \mu \mathrm{g} \mathrm{mL}^{-1}$ for the $\left.\mathrm{SaF}\right)$. Intermediate precision was determined by spiking the same concentration levels, prepared in triplicate on three different days. The precision of the results was expressed by $\%$ RSD (relative standard deviation).

Accuracy was assessed by a recovery study processed in the same way as the repeatability work. Calculations of accuracy were based on comparison of the theoretical and the measured concentrations.

Robustness was corroborated by deliberate method modifications. Investigation of little differences in the elution gradient was conducted (Tests 1, 2 and 3). Test 1 was carried out as described in the "HPLC-DAD conditions" section from 0 to $14 \mathrm{~min}$ and from 26 to $30 \mathrm{~min}$, with changes from 50 to $65 \%$ of B in $11 \mathrm{~min}$ and from 65 to $90 \%$ of $\mathrm{B}$ in $1 \mathrm{~min}$. Test 2 was performed using a change from 30 to $40 \%$ of B in $7 \mathrm{~min}, 40 \%$ of B for $7 \mathrm{~min}$, from 40 to $55 \%$ of $\mathrm{B}$ in $1 \mathrm{~min}$ and then the same as described in the
"HPLC-DAD conditions" section from 15 to $30 \mathrm{~min}$. Test 3 was run according to "HPLC-DAD conditions" section from 0 to $14 \mathrm{~min}$ and from 26 to $30 \mathrm{~min}$, varying only from 50 to $55 \% \mathrm{~B}$ in $1 \mathrm{~min}$, from 55 to $65 \% \mathrm{~B}$ in $9 \mathrm{~min}$, from 65 to $90 \% \mathrm{~B}$ in $1 \mathrm{~min}$ and keeping $40 \%$ of B over $1 \mathrm{~min}$.

Another test for robustness consisted of the replacement of the column by another C8 column (ACE, $150 \times 4.6 \mathrm{~mm}, 5 \mu \mathrm{m}, 10 \mathrm{~nm}$ pore size, surface area of $300 \mathrm{~m}^{2} \mathrm{~g}^{-1}$ ). This column had similar specifications to the one used in the original method, except for its surface area and brand.

\section{Method application}

The practicability of the validated method was checked with real red wine samples from the Campanha Gaúcha region, as described under the "Samples of red wines" section. All quantified analytes of these samples had their peaks compared with standards in terms of $t_{\mathrm{R}}$, UV/VIS (ultraviolet/visible) spectra and purity.

\section{Statistical analysis}

Recovery, precision, robustness, linearity assessments, ANOVA, determination of calibration curve and $r^{2}$ were calculated using Excel 2013 software (Microsoft Corp., Redmond, United States), being confirmed through OriginPro 8 software (v8.0724) (OriginLab Corp., United States).

\section{Results and discussion}

\section{Development of HPLC-DAD method}

In this study, the focus was on developing a very selective method for the analysis of the largest possible number of markers of $\mathrm{SaF}$ biosynthetic pathways in red wines using an accessible technique (HPLC-DAD). To accomplish this goal, the method was exhaustively tested under the conditions presented in Table 1, and then optimized. Observations on the performance of the system suitability are also presented, namely $R_{\mathrm{s}}$ and TF for each methodological variation. $R_{\mathrm{S}}$, which measures the separation between two peaks, is recommended to be over 2.0 (FDA US Food and Drug Administration 1994). The $R_{\mathrm{s}}$ values between most analytes and the adjacent peaks were at least 2.0, ensuring an adequate chromatographic separation (Table 2). The $R_{\mathrm{s}}$ of resveratrol was close to 2.0. However, some authors recommend acceptance criteria with $R_{\mathrm{s}}$ less than 1.5 (Bliesner 2006; FDA US Food and Drug Administration 1994). Considering the high purity of the resveratrol peak, the $R_{\mathrm{s}}$ close to 2.0 did not cause error of integration. 
Table 1 HPLC conditions during $\mathrm{SaF}$ and trans-cinnamic acid method development

\begin{tabular}{|c|c|c|c|c|c|c|}
\hline \multicolumn{4}{|c|}{ Column } & \multirow{2}{*}{$\begin{array}{l}\text { Eluent }^{\mathrm{b}} \\
\text { Organic }^{\mathrm{c}}\end{array}$} & \multicolumn{2}{|c|}{ System suitability } \\
\hline Phase & Dimensions $(\mathrm{mm})^{\mathrm{a}}$ & Particle $(\mu \mathrm{m})$ & Pore size $(\mathrm{nm})$ & & $\mathrm{TF}$ & $R_{\mathrm{s}}$ \\
\hline $\mathrm{C} 18$ & $250 \times 4.6$ & 5.0 & 12 & $\mathrm{ACN}$ & $>2.0$ & $<1.5$ \\
\hline $\mathrm{C} 18$ & $250 \times 4.6$ & 5.0 & 12 & $\mathrm{MeOH}$ & $\leq 2.0$ & $<1.5$ \\
\hline $\mathrm{C} 18$ & $150 \times 4.6$ & 5.0 & 12 & $\mathrm{ACN}$ & $>2.0$ & $<1.5$ \\
\hline $\mathrm{C} 18$ & $150 \times 4.6$ & 5.0 & 12 & $\mathrm{MeOH}$ & $\leq 2.0$ & $<1.5$ \\
\hline $\mathrm{C} 18$ & $150 \times 4.6$ & 2.6 & 10 & $\mathrm{ACN}$ & $>2.0$ & $<1.5$ \\
\hline $\mathrm{C} 18$ & $150 \times 4.6$ & 2.6 & 10 & $\mathrm{MeOH}$ & $>2.0$ & $<1.5$ \\
\hline $\mathrm{C} 8$ & $150 \times 4.6$ & 5.0 & 10 & $\mathrm{ACN}$ & $\leq 2.0$ & $<1.5$ \\
\hline $\mathrm{C} 8$ & $150 \times 4.6$ & 5.0 & 10 & $\mathrm{MeOH}$ & $\leq 2.0$ & $>2.0$ \\
\hline
\end{tabular}

${ }^{a}$ Length and internal diameter of column

b Same gradient conditions as described in "HPLC-DAD conditions" section. Use of methanol (MeOH) or acetonitrile (ACN)

c Aqueous/organic ratio was constant. Organic phase was always $90 \%$ (V/V in water), and formic acid was added to this to give $0.1 \% \mathrm{~V} / \mathrm{V}$. Aqueous phase was fixed (formic acid $0.1 \% \mathrm{~V} / \mathrm{V}$ )

d System suitability in terms of TF and $R_{\mathrm{s}}$, with acceptable values of $\leq 2.0$ and $>2.0$, respectively (FDA, US Food and Drug Administration 1994)

Table 2 Analytical characteristics and selectivity (values \pm SD) of the HPLC-DAD method for SaF and trans-cinnamic acid standards, according to section "HPLC-DAD conditions"

\begin{tabular}{|c|c|c|c|c|c|c|c|}
\hline Parameters & Recomendation $^{\mathrm{a}}$ & Trans-cinnamic acid & Trans-resveratrol & Trans-£-viniferin & Kaempferol & Quercetin & Myricetin \\
\hline \multicolumn{8}{|c|}{ Detection characteristics $^{\mathrm{b}}$} \\
\hline$t_{\mathrm{R}}(\min )$ & $t_{\mathrm{R}} \pm 1.0$ & $23.38 \pm 0.16$ & $15.63 \pm 0.20$ & $21.78 \pm 0.08$ & $26.65 \pm 0.21$ & $22.53 \pm 0.13$ & $16.91 \pm 0.32$ \\
\hline$\lambda_{\max }(\mathrm{nm})$ & - & 276 & 306 & 322 & 365 & 371 & 374 \\
\hline \multicolumn{8}{|c|}{ System suitability $^{c}$} \\
\hline$k$ & $>2.0$ & $13.23 \pm 0.05$ & $8.57 \pm 0.05$ & $12.50 \pm 0$ & $15.47 \pm 0.05$ & $12.67 \pm 0.30$ & $9.37 \pm 0.05$ \\
\hline$R_{\mathrm{s}}$ & $>2.0$ & $2.25 \pm 0.08$ & $2.18 \pm 0.04$ & $4.38 \pm 0.52$ & $9.22 \pm 0.09$ & $7.13 \pm 0.50$ & $3.05 \pm 1.42$ \\
\hline $\mathrm{TF}$ & $\leq 2.0$ & $1.0 \pm 0$ & $0.97 \pm 0.05$ & $0.92 \pm 0.04$ & $1.05 \pm 0.05$ & $1.03 \pm 0.05$ & $1.02 \pm 0.04$ \\
\hline$N$ & $>2000$ & $71202 \pm 764$ & $11872 \pm 461$ & $54081 \pm 3098$ & $41161 \pm 1018$ & $42283 \pm 444$ & $8923 \pm 326$ \\
\hline \multicolumn{8}{|l|}{ Selectivity $^{\mathrm{c}}$} \\
\hline$t_{\mathrm{R}}(\min )$ & $t_{\mathrm{R}} \pm 1.0$ & $23.06 \pm 0.05$ & $15.33 \pm 0.08$ & $21.60 \pm 0.03$ & $26.34 \pm 0.03$ & $22.22 \pm 0.02$ & $16.58 \pm 0.08$ \\
\hline$\lambda_{\max }(\mathrm{nm})$ & - & 276 & 306 & 322 & 365 & 371 & 374 \\
\hline Purity & - & $>0.99$ & 1.00 & 1.00 & $>0.99$ & $>0.99$ & $>0.99$ \\
\hline
\end{tabular}

${ }^{a}$ According to Bliesner (2006), FDA US Food and Drug Administration (1994) and Shabir (2003)

b Determined by DAD detector for each analytical standard (Fig. 2a)

${ }^{c}$ Determined at $\lambda_{\max }$ of each $\mathrm{SaF}$ of a spiked wine $\left(n=6\right.$, low level $\left.=10 \mu \mathrm{g} \mathrm{mL}^{-1}\right)$

The selectivity using a DAD detector has been previously reported, but with the use of an UPLC instrument (Silva et al. 2011). In addition, the TF of a peak should be equal to, or less than, 2.0 in order not to have tailing complicate the integration (Bliesner 2006; FDA US Food and Drug Administration 1994).

Guidelines require that the system suitability is shown to be acceptable before method validation (ANVISA 2003; FDA US Food and Drug Administration 2001). The only tested method that was in compliance with this requirement was using a C8 column and an organic mobile phase composed of methanol (see "HPLC-DAD conditions" section). Given its suitability, this method was chosen to be validated. Detection characteristics of this method, like $t_{\mathrm{R}}$ and $\lambda_{\max }$ are described in Table 2. Since the analytes studied all have a very strong chromophore, they also proved to have high enough molar absorptivity to be detectable by UV (Kazakevich and Lobrutto 2007). Nevertheless, the method is suitable for the DAD detector instead of a UV/VIS one, since the specific $\lambda_{\max }$ of each analyte is required for their detection. SaF and trans-cinnamic acid have different properties of $\lambda_{\max }$ and polarity, 


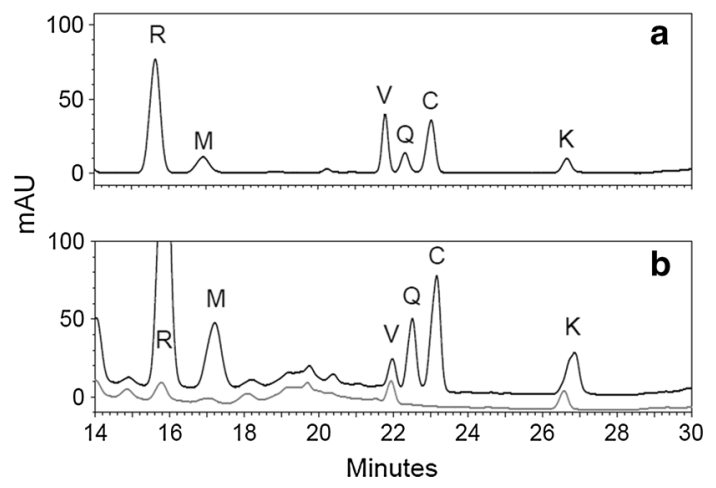

Fig. 1 HPLC-DAD chromatograms obtained according to parameters defined in "HPLC-DAD conditions" section: standard mixture with $10 \mu \mathrm{g} \mathrm{mL}^{-1}$ of each analyte at $306 \mathrm{~nm}(\mathbf{a})$; overlaid at $306 \mathrm{~nm}$ for unspiked red wine (bottom line) and red wine spiked (top line) with a standard mixture of analytes (b). Peak identifications: transresveratrol $(\mathrm{R})$, myricetin $(\mathrm{M})$, trans- $\varepsilon$-viniferin $(\mathrm{V})$, quercetin $(\mathrm{Q})$, trans-cinnamic acid $(\mathrm{C})$ and kaempferol $(\mathrm{K})$

evidenced by different $t_{\mathrm{R}}$ values. In this study, such specific differences were fully explored to separate each analyte and to obtain a pure peak.

HPLC-DAD chromatograms at $306 \mathrm{~nm}$ demonstrated good peak separation (Fig. 1) allowing suitable identification of each peak (Fig. 2). The chromatogram of a solution containing a mixture of standards at $10 \mu \mathrm{g} \mathrm{mL}^{-1}$ is presented in Fig. 1a. A comparison of a typical red wine chromatogram with a spiked red wine $\left(10 \mu \mathrm{g} \mathrm{mL}^{-1}\right.$ of analytical standards) is illustrated in Fig. $1 \mathrm{~b}$, recorded at $306 \mathrm{~nm}$. The analytical profile of each analyte was then established using the developed method.

The system suitability of parameters under the test conditions is also described in Table 2. The obtained values for all analytes in the low level spiked wine (2.5 $\mu \mathrm{g} \mathrm{mL}^{-1}$ for cinnamic acid, and $10 \mu \mathrm{g} \mathrm{mL}^{-1}$ for other $\mathrm{SaF}$ ) were according to recommendations (FDA US Food and Drug Administration 1994).

The use of a C8 column for SaF and trans-cinnamic acid analysis is different to most published HPLC methods, that use C18 phase columns instead (Careri et al. 2004; Cotea et al. 2012; López et al. 2001; Malovaná et al. 2001; Tenore et al. 2011). Determination of trans-resveratrol has been conducted with a column similar to the one used in this research (Zhou et al. 2004), i.e., it had the same technical specifications, but that study used an isocratic elution. The columns with a $\mathrm{C} 8$ phase are less hydrophobic than those with a $\mathrm{C} 18$ phase. Compared to $\mathrm{C} 18$, a $\mathrm{C} 8$ column decreases the retention of moderately polar compounds (Kazakevich and Lobrutto 2007), like SaF and trans-cinnamic acid. These characteristics were fully explored and found to give suitable separation and represented an advantage in method optimization. Then, a C8 phase column may be a good option to obtain the desirable
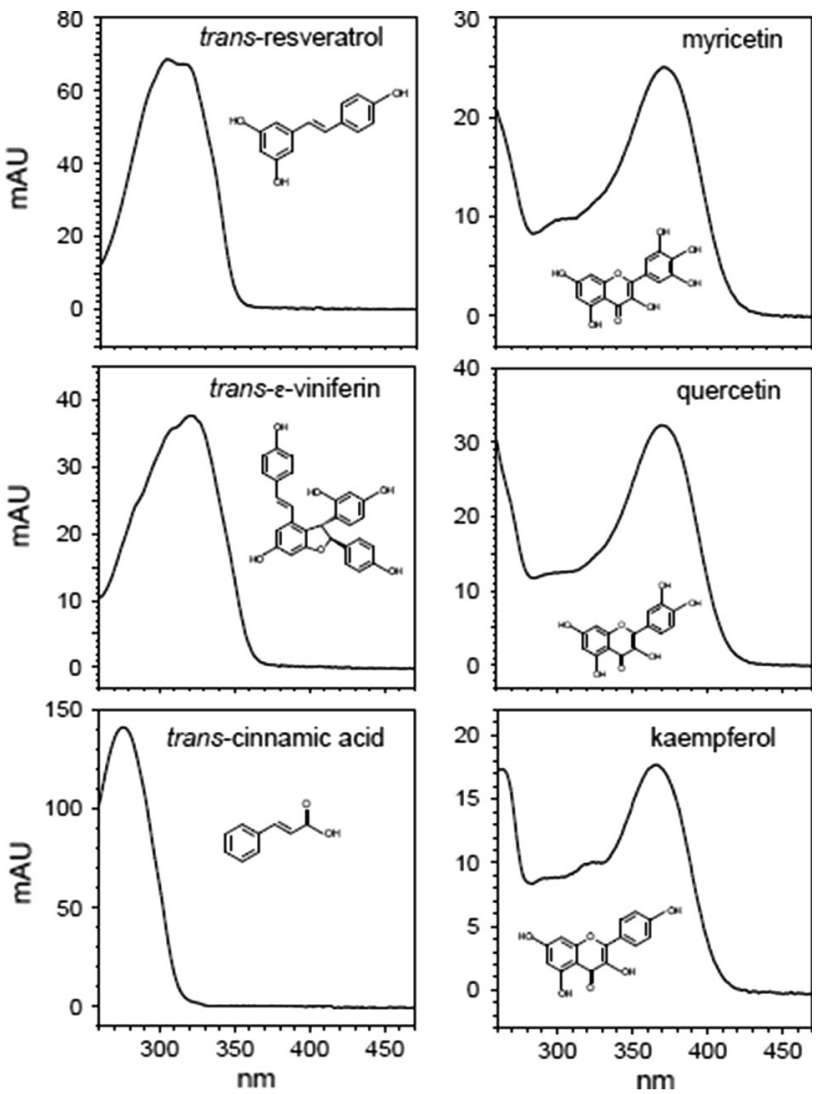

Fig. 2 Set of UV spectra for all the analytes, with their corresponding chemical structures

system suitability, selectivity and a fast chromatographic run for the HPLC standards (30 $\mathrm{min})$.

\section{Method validation}

The method was considered suitable in terms of the performance characteristics defined by FDA US Food and Drug Administration (2001) and ANVISA (2003) guidelines, namely: selectivity, linearity, LOD, LOQ, precision, accuracy and robustness. Calibration results are reported in Table 3. Precision, accuracy and robustness are exposed in Table 4.

The primary method selectivity was verified by the classic crossing DAD data of UV spectra (Fig. 2), purity index (at least 0.99 ) and $t_{\mathrm{R}}$ (standard deviation-SD $<1$ ) of the analytes. Previous methods have used only this simplified approach, or something even less rigorous, to check the selectivity (Castellari et al. 2002; Cotea et al. 2012; Kerem et al. 2004; Lima et al. 1999; Malovaná et al. 2001; Paulo et al. 2011; Pereira et al. 2010; Pérez-Magarino et al. 2008; Villiers et al. 2004). Some of these published chromatograms had critical regions of elution with wide unknown peaks and baseline deviation, as demonstrated in Fig. 1. This does not impair the use of the method, but 


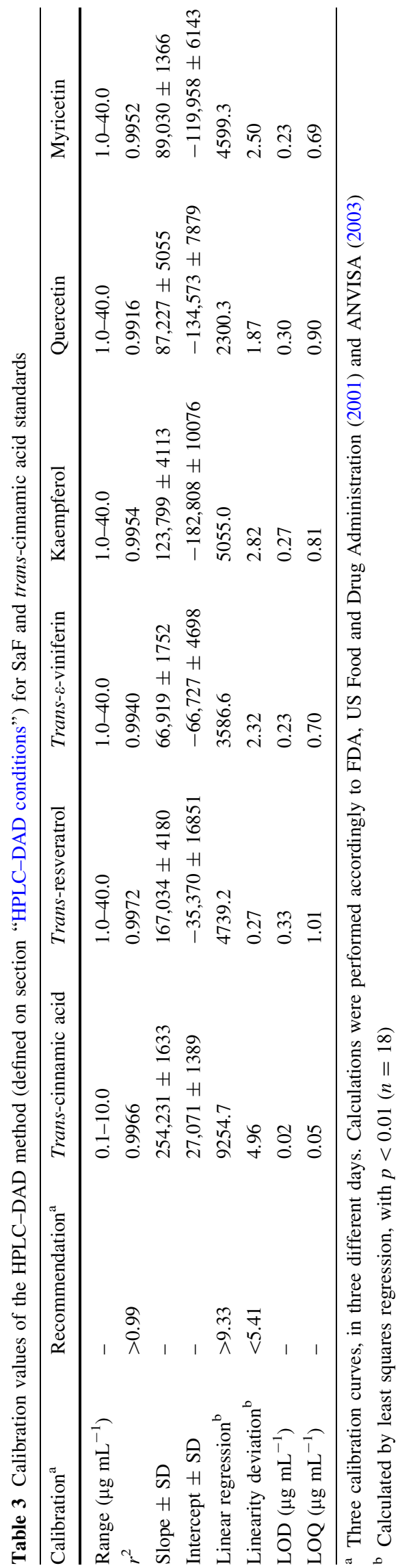

during validation it is recommended that a thorough knowledge of the interferences and their identities and $t_{\mathrm{R}}$ values be acquired (ANVISA 2003; FDA US Food and Drug Administration 2001). For these reasons, we conducted an exhaustive exploration of the DAD and QTOF data obtained from the chromatograms of red wines analyzed by the developed method. Chromatograms recorded at $525 \mathrm{~nm}$ (Fig. 3a), in the visible region, suggested the presence of anthocyanic pigments, according to a well know UV/VIS profile (Burns et al. 2002; OIV International Organization of Vine and Wine 2015). The three-dimensional graph (Fig. 3b) also illustrates an intense absorption $(\mathrm{mAU})$ where these interferences elute through a range of $t_{\mathrm{R}}$ : from 0 to $15.0 \mathrm{~min}$, from 19.0 to $21.3 \mathrm{~min}$ and after $28 \mathrm{~min}$. QTOF data confirmed the interference of anthocyanic pigments and other phenols in these three $t_{\mathrm{R}}$ ranges, showing higher total ion counts through the chromatogram and also their characteristic $\mathrm{m} / \mathrm{z}$ for molecular ions and fragments in positive mode $\left(\mathrm{ESI}^{+}\right)$in accordance with previous publications (Burns et al. 2002; De Rosso et al. 2012; Flamini 2003; Gordillo et al. 2012; OIV International Organization of Vine and Wine 2015; Wu et al. 2005). The main interferences occurred from 0 to $15.0 \mathrm{~min}$, where the combined mass spectra registered $\mathrm{m} / \mathrm{z}$ 291.09, 579.13 and 867.18 which are compatible with wine flavanols (Fig. 3c). Trace levels of some nonacylated anthocyanins $(\mathrm{m} / \mathrm{z}, 479.08$ and 465.09) were also detected through the first $15 \mathrm{~min}$ (Fig. 3d). From 19.0 to $21.3 \mathrm{~min}$, a high quantity of malvidin-3-O-glucoside $(\mathrm{m} / \mathrm{z}, 493.14$, and its fragment $\mathrm{m} / \mathrm{z}, 331.10)$ and peonidol-3-O-glucoside $(\mathrm{m} / \mathrm{z}$ 462.14) were found (Fig. 3e). Additionally, the sensitivity of QTOF, over that of the DAD, enabled the detection of acetylated $(\mathrm{m} / \mathrm{z} 505.14,535.15)$ and coumarylated $(\mathrm{m} / \mathrm{z}$ 639.17) anthocyanins that seem to appear after $28 \mathrm{~min}$ (Fig. 3f).

Anthocyanins, which are responsible for the color of red wines, and flavanols were the major interfering compounds in this analysis of $\mathrm{SaF}$ and trans-cinnamic acid in red wines. To ensure system suitability, it was necessary to identify a safety region to perform selective determinations of $\mathrm{SaF}$ and trans-cinnamic acid by direct injection of red wine in HPLC, that is: from 15.0 to $19.0 \mathrm{~min}$ and from 21.3 to $28 \mathrm{~min}$. Absorptions by the interferents did not occur in the visible range at the $t_{\mathrm{R}}$ defined for analysis.

Linearity was observed for all analytes, over their concentration ranges and $r^{2}>0.99$. ANOVA confirmed a linear relationship $\left(F_{\text {calc }}>F_{\text {tab }}, p<0.01\right)$ and no deviation from linearity ( $\left.F_{\text {calc }}<F_{\text {tab }}, p>0.01\right)$. The calibration curves covered the range of analyte concentrations normally found in red wines (Adrian et al. 2000; Castellari et al. 2002; Fontana and Bottini 2014; Lima et al. 1999; López et al. 2001; Malovaná et al. 2001; Vitrac et al. 2005). Linearity, LOD and LOQ for each SaF and trans- 
Table 4 Precision, accuracy and robustness of the HPLC-DAD method for SaF and trans-cinnamic acid analysis in cabernet sauvignon red wine

\begin{tabular}{|c|c|c|c|c|c|c|c|}
\hline Parameters & Recommendation $^{\mathrm{a}}$ & Trans-cinnamic acid & Trans-resveratrol & Trans- $\varepsilon \varepsilon$-viniferin & Kaempferol & Quercetin & Myricetin \\
\hline \multicolumn{8}{|c|}{ Repeatability (\%RSD)* } \\
\hline $\mathrm{L}$ & $<15$ & 1.98 & 1.78 & 1.85 & 3.55 & 4.63 & 4.04 \\
\hline M & $<15$ & 0.94 & 1.90 & 1.35 & 5.11 & 4.44 & 4.15 \\
\hline $\mathrm{H}$ & $<15$ & 0.51 & 1.27 & 3.36 & 3.52 & 1.88 & 1.17 \\
\hline \multicolumn{8}{|c|}{ Intermediate precision $(\% \mathrm{RSD}) *$} \\
\hline $\mathrm{L}$ & $<15$ & 5.56 & 5.65 & 3.20 & 8.03 & 7.48 & 5.24 \\
\hline M & $<15$ & 4.41 & 3.09 & 5.28 & 8.49 & 7.61 & 6.00 \\
\hline $\mathrm{H}$ & $<15$ & 3.78 & 4.58 & 4.97 & 9.16 & 8.48 & 5.37 \\
\hline \multicolumn{8}{|c|}{ Accuracy (\%recovery)* } \\
\hline $\mathrm{L}$ & $85-115$ & 94.66 & 101.30 & 106.27 & 101.32 & 97.94 & 101.52 \\
\hline M & $85-115$ & 102.57 & 102.48 & 100.98 & 103.62 & 98.70 & 99.77 \\
\hline $\mathrm{H}$ & $85-115$ & 102.07 & 105.86 & 106.95 & 87.40 & 90.12 & 86.70 \\
\hline \multicolumn{8}{|c|}{ Robustness (RT) } \\
\hline Elution-test 1 & - & 23.91 & 17.03 & 22.48 & 27.54 & 22.97 & 17.80 \\
\hline Elution-test 2 & - & 23.15 & 17.76 & 21.72 & 25.74 & 22.98 & 19.02 \\
\hline
\end{tabular}

The method is as described in the "HPLC-DAD conditions" section

* Spiked wine with three level of each analytical standard of SaF, defined on section "Method validation" ( $L$ low, $M$ medium and $H$ high)

cinnamic acid analysis are presented in the calibration curve data (Table 3).

Intra-day and inter-day precisions were acceptable because the \%RSD between determinations did not exceed 15\% (Table 4). In general, kaempferol and quercetin had higher \%RSD than the other analytes. They are also the most hydrophobic of the compounds present in high concentrations, i.e., excluding cinnamic acid. Probably their solubilities in wine, with around $12 \%$ or $14 \%$ GL alcohol, were lower than those of the other analytes. However, such characteristic did not interfere in the method validation. As a result, the HPLC-DAD method was demonstrated to be precise for repeatability and intermediate precision.

Accuracy was demonstrated by suitable recoveries of all analytes (from 85 to $115 \%$ ), as prescribed by the FDA US Food and Drug Administration (2001). The lowest determined values were for kaempferol, quercetin and myricetin, presumably for similar reasons explained above. The developed method was accurate for the required purpose, demonstrated no remarkable matrix effect (Table 4). Additionally, all identities were confirmed by UV spectra.

The developed method was robust, as some small modifications to its conditions did not affect the results (Table 4). Changing the gradient elution, the values of some $t_{\mathrm{R}}$ were modified. Nevertheless, purities were kept within acceptable values. Furthermore, quantifications did not deviate more than 5.0\% (\%RSD). Thus, the method was considered robust enough to be included in the routine repertoire of a laboratory.

Further and more significant alterations to the method were also tried by changing the $\mathrm{C} 8$ column for another one, but of a different brand and surface area. This second C8 column tested promoted separation of all compounds, except for viniferin and quercetin (Table 2). Viniferin had a $t_{\mathrm{R}}$ of $21.01 \mathrm{~min}$ and eluted very close to quercetin $(21.18 \mathrm{~min})$. UV/VIS detection of viniferin $\left(\lambda_{\max }=322\right.$ $\mathrm{nm})$ did not affect the detection of quercetin $\left(\lambda_{\max }=371 \mathrm{~nm}\right)$. However, the opposite did not hold, since quercetin absorbs at $322 \mathrm{~nm}$ (Fig. 2). For this reason, viniferin could not be determined with this tested column without other alterations in the original method described under "HPLC-DAD conditions" section.

\section{Application of HPLC method in red wine}

In this study, the first goal was not necessarily to elucidate which of the wines from a region would be richest in their $\mathrm{SaF}$ markers. Before this comparison could be undertaken, it was necessary to put the current selective and validated HPLC-DAD method into practice to demonstrate its applicability as a feasible tool for the evaluation of red wines. Considering that wines are complex samples and their phenolic profiles are affected mainly by the grape variety, six varieties from the same region (Campanha Gaúcha) were tested to check the method selectivity. Therefore, the red wine samples were submitted to the method and their SaF markers were measured. Sample analyte peaks were comparable with those in standard profiles, including purity index $(>0.99), t_{\mathrm{R}}(\mathrm{SD}<1)$ and UV/VIS spectra (Table 2; Figs. 1, 2).

The concentrations of five SaF and trans-cinnamic acid in red wines determined by this HPLC-DAD method are 
a

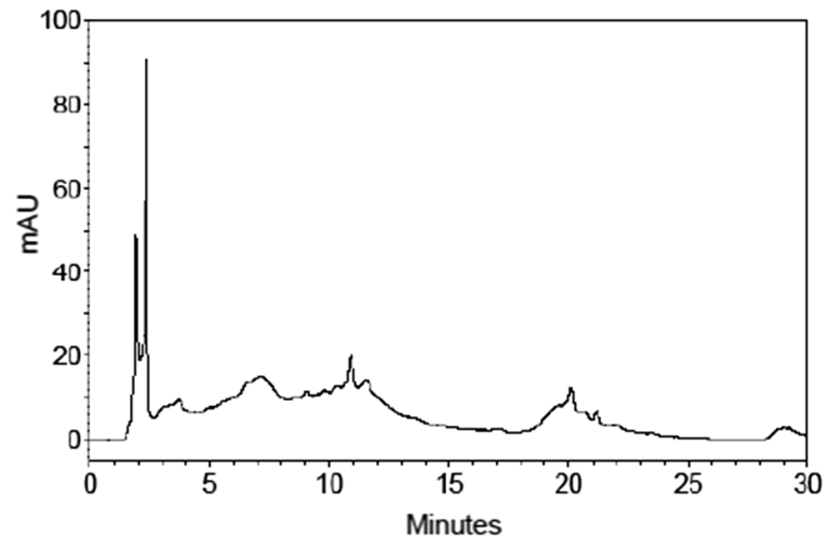

C

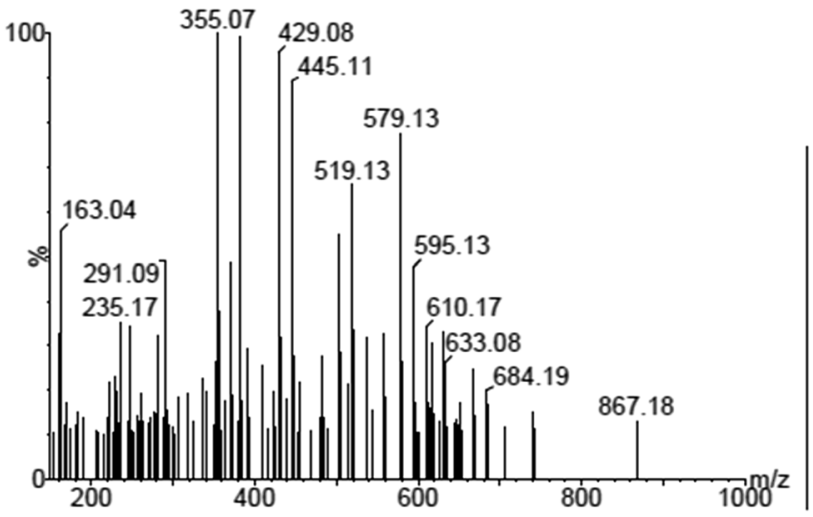

e

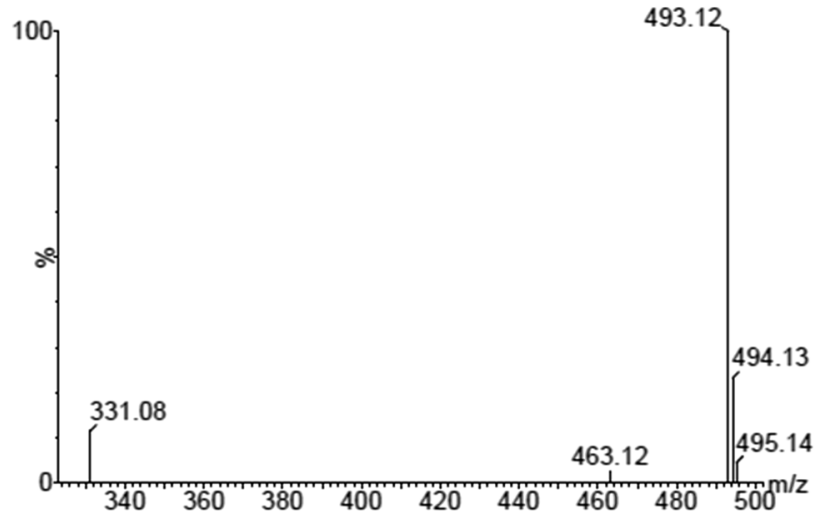

Fig. 3 Selectivity data for a sample of red wine showing no interference of anthocyanins with $\mathrm{SaF}$ and trans-cinnamic acid: HPLC-DAD chromatogram at $525 \mathrm{~nm}$ (a); 3D graph (b); mass spectrum of flavanol interferences, scanned from 0 to $15 \mathrm{~min}(\mathbf{c})$; mass spectrum of anthocyanic interferences, scanned from 0 to

given in Table 5. The \%RSD was higher for the lower SaF concentrations, but they could be reduced by employing an automated injector. The data presented were collected using a manual injector, taking into account analyst operation errors. Furthermore, trans-cinnamic acid and b

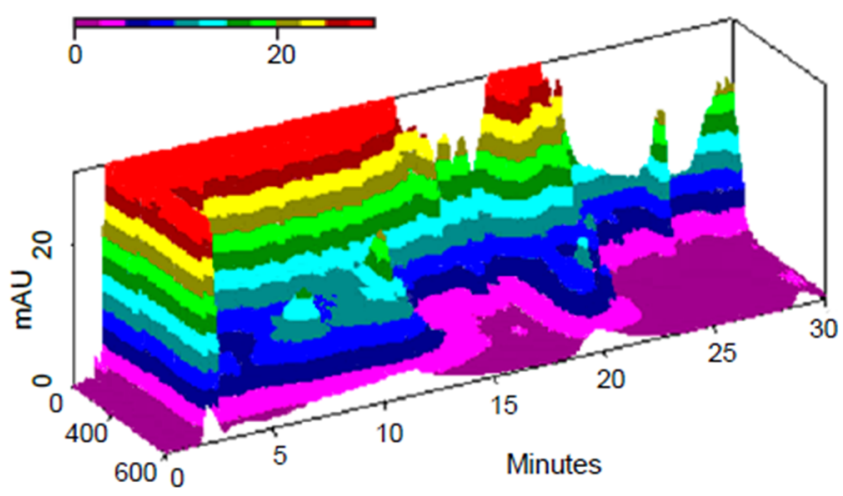

d

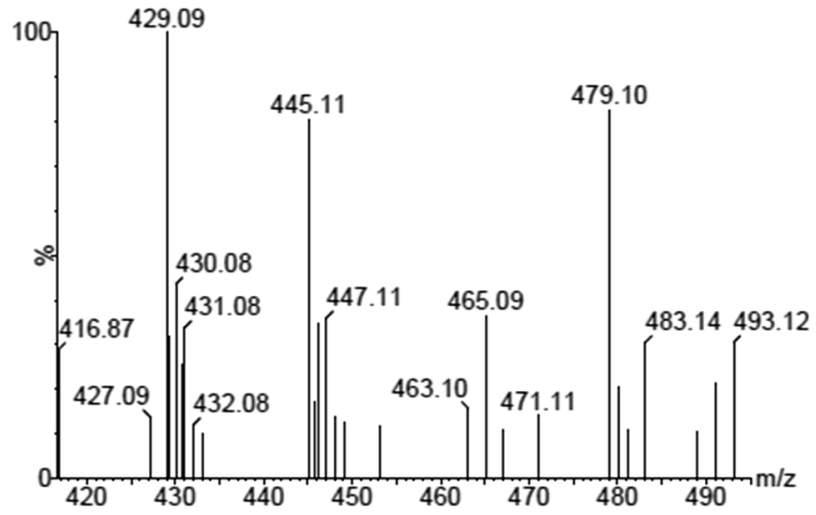

f

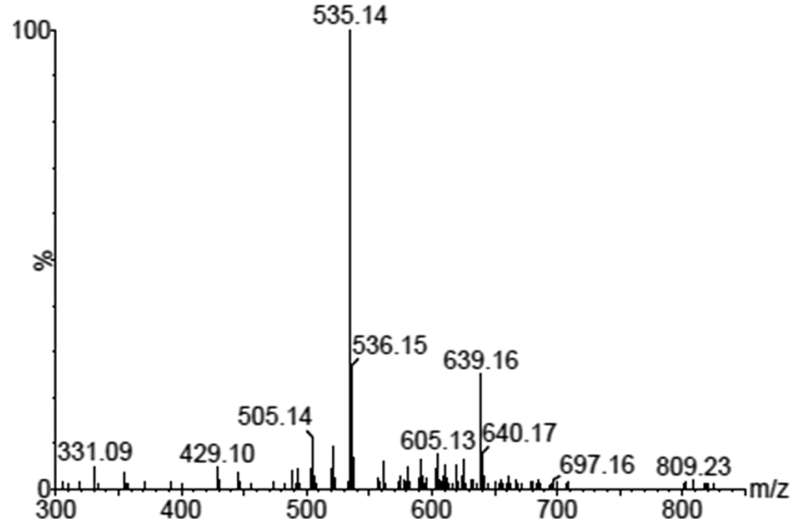

15 min (d); mass spectrum of anthocyanic interferences, scanned from 19 to $21.3 \mathrm{~min}(\mathbf{e})$; mass spectrum of anthocyanic interferences, scanned from 28 to $30 \mathrm{~min}$ (f). For conditions of HPLC-DAD and QTOF, see "HPLC-DAD conditions" and "Method validation" sections, respectively

kaempferol showed the higher \%RSD, but this is explicable by their low level and low solubility, respectively.

This is the first SaF characterization known for wines from the Campanha Gaúcha region. An exploration of the presented results, or the application of the same method for 
Table 5 Concentration of SaF markers and trans-cinnamic acid in commercial red wines samples from Campanha Gaúcha, according to the method described under "HPLC-DAD conditions" section

\begin{tabular}{|c|c|c|c|c|c|c|c|c|c|}
\hline \multirow[t]{2}{*}{ Wine variety } & \multicolumn{6}{|c|}{ Concentration $^{\mathrm{a}}\left(\mu \mathrm{g} \mathrm{mL}^{-1}\right)$} & \multirow[t]{2}{*}{ Stilbenes $^{\mathrm{b}}$} & \multirow[t]{2}{*}{ Flavonols $^{\mathrm{c}}$} & \multirow{2}{*}{$\begin{array}{l}\text { Markers } \\
\text { of } \mathrm{SaF}^{\mathrm{d}}\end{array}$} \\
\hline & $\begin{array}{l}\text { Trans-cinnamic } \\
\text { acid }\end{array}$ & $\begin{array}{l}\text { Trans- } \\
\text { resveratrol }\end{array}$ & $\begin{array}{l}\text { Trans- } \varepsilon^{-} \\
\text {viniferin }\end{array}$ & Kaempferol & Quercetin & Myricetin & & & \\
\hline Cabernet franc & ND & ND & $1.85(3.06)$ & ND & $4.01(4.21)$ & $2.37(3.81)$ & 1.85 & 6.38 & 8.23 \\
\hline $\begin{array}{l}\text { Cabernet } \\
\text { sauvignon }\end{array}$ & $<0.05$ & $3.65(5.44)$ & $3.32(3.42)$ & $2.01(8.03)$ & $5.19(2.05)$ & $7.86(0.73)$ & 6.97 & 15.06 & 22.08 \\
\hline Malbec & $<0.05$ & $2.37(0.83)$ & $1.95(1.39)$ & $1.78(1.18)$ & $4.64(1.23)$ & $8.07(1.07)$ & 4.32 & 14.49 & 18.86 \\
\hline Merlot & $0.07(8.13)$ & $8.61(4.36)$ & $2.92(0.41)$ & ND & $<0.90$ & $3.80(4.56)$ & 11.53 & 4.70 & 16.3 \\
\hline Tannat & $<0.05$ & $1.78(2.76)$ & $2.79(4.34)$ & $1.74(4.70)$ & $4.06(0.94)$ & $3.61(4.23)$ & 4.57 & 9.41 & 14.03 \\
\hline Tempranillo & $<0.05$ & $5.27(3.62)$ & $5.31(2.42)$ & $1.87(4.45)$ & $4.58(5.46)$ & $8.94(3.96)$ & 10.58 & 15.39 & 26.02 \\
\hline \multicolumn{10}{|l|}{$N D$ not detected } \\
\hline \multicolumn{10}{|c|}{${ }^{\mathrm{a}}$ Mean value and $\%$ RSD (in brackets), $n=3$} \\
\hline \multicolumn{10}{|c|}{ b Sum of trans-resveratrol and trans- $\varepsilon$-viniferin } \\
\hline \multicolumn{10}{|c|}{${ }^{\mathrm{c}}$ Sum of kaempferol, quercetin, and myricetin } \\
\hline
\end{tabular}

new samples, may contribute for Certificate of Origin and strategies for the design of new products in this region (Ribéreau-Gayon et al. 2006). Here, the majority of the results were within the linear range of the method for each analyte.

Regarding each specific compound, viniferin, quercetin and myricetin were more frequently found than transresveratrol and kaempferol. Cinnamic acid was detected in a few samples and only quantified in one Merlot sample $\left(0.07 \mu \mathrm{g} \mathrm{mL}^{-1}\right)$. The biosynthesis of $\mathrm{SaF}$ requires consumption of cinnamic acid, which is the first compound derived from phenylalanine (Pereira et al. 2010; Silva et al. 2011; Tenore et al. 2011). Generally, when this pathway to $\mathrm{SaF}$ is active, trans-cinnamic acid is present at low levels, whereas the SaF concentrations are high (Ribéreau-Gayon et al. 2006; Silva et al. 2011).

In general, the results presented in this study agreed with other studies previously reported for red wines (Adrian et al. 2000; Castellari et al. 2002; Fontana and Bottini 2014; Lima et al. 1999; López et al. 2001; Malovaná et al. 2001; Vitrac et al. 2005), which were similar in terms of the range of each $\mathrm{SaF}\left(\mu \mathrm{g} \mathrm{mL}^{-1}\right)$ present. More detailed comparisons among varieties or regions with those publications are meaningless, because the samples were analysed using different methods and conditions. Furthermore, other investigations proved that levels of $\mathrm{SaF}$ in wines are influenced by several factors like vineyard management, climatic conditions, vinification technology and grapevine variety (Carbonell-Bejerano et al. 2014). Despite this, clearly the developed method is usable and suitable for distinguishing samples through the analytes. This current HPLC-DAD method has several advantages over the previous published methods (Adrian et al. 2000; Aznar et al. 2011; Baptista et al. 2001; Careri et al. 2004; Castellari et al. 2002; Cotea et al. 2012; Fontana and Bottini 2014; Gómez-Alonso et al., 2007; Kerem et al. 2004; Lima et al. 1999; López et al. 2001; Malovaná et al. 2001; Pereira et al. 2010; Pérez-Magarino et al. 2008; Rastija et al. 2009; Revilla and Ryan 2000; Villiers et al. 2004; Vitrac et al. 2005). These include very simple sample preparation, high selectivity, fast analysis, full reported validation, with widely available instrumentation and it has been tested through analysis of different varieties of real wine samples. In summary, we have showed the compliance of this HPLC method to determine markers of SaF biosynthetic pathway in red wines.

\section{Conclusions}

QTOF provided the confirmation of analyte selectivity in a feasible HPLC-DAD method for the chemical characterization of the products of $\mathrm{SaF}$ biosynthetic pathways, through a simultaneous determination of trans-resveratrol, trans- $\varepsilon$-viniferin, quercetin, kaempferol, myricetin and trans-cinnamic acid in red wines. The developed method combines several methodological advantages to determine markers of bioactive SaF in red wines (Cabernet Franc, Cabernet Sauvignon, Malbec, Merlot, Tannat and Tempranillo). Validation results demonstrated that the proposed method is linear, sensitive, precise, accurate for each analyte, and robust. During validation, QTOF and DAD supported the establishment of the secure range of $t_{\mathrm{R}}$ to evaluate the analytes, avoiding overestimation of the results by coelution of the main interferents (anthocyanic pigments and flavanols). This method may be performed in any simple HPLC-DAD system, following the methodology recommendations in observing the analyte profiles on 
DAD detectors. The sample preparation and handling are very simple and minimize analytical errors.

The method appears to be useful in routine analysis, being selective and feasible. The analysis of wines from the Campanha Gaúcha region, Brazil, proved that the method might be used for successful wine designs. Using those $\mathrm{SaF}$ as markers of the nutraceutical grade of a wine it is possible to study the quality of the product. It may also be employed to establish the optimal conditions of field management, vinification technologies and potential regions for each grape variety. Finally, the proposed technique can potentially contribute to agriculture and wine making, not only in the new Brazilian grape regions, because it may be extrapolated to other regions and samples. This HPLCDAD method could be further adapted for the aglycone $\mathrm{SaF}$ and trans-cinnamic acid analysis of other wine varieties, grapes, grape by-products (e.g., juices), fruits, processed foods or beverages, following the specific sample preparation when necessary.

Acknowledgements Commercial samples of wines were kindly collected by Dr. Jorge Tonietto from Embrapa Uva e Vinho and his team (Brazilian Agricultural Research Corporation-Grape and Wine). The authors gratefully acknowledge the FINEP (Brazilian Innovation Agency) and PPGCF-UFRGS (Pharmaceutical Sciences Graduate Program-Federal University of Rio Grande do Sul) for the financial support. The authors also thank Stephani Amanda Lukasewicz Ferreira for reviewing the manuscript, Alessandra Russi for the illustrations and Dr. Fabio Rossi Cavalcanti for the statistical confirmations by OriginPro 8 software.

\section{References}

Adrian M, Jeandet P, Breuil AC, Levite D, Debord S, Bessisn R (2000) Assay of resveratrol and derivative stilbenes in wines by direct injection high perfor 'mance liquid chromatography. Am J Enol Vitic 51(1):37-41

ANVISA (2003) Resolução n.899 de 29 de maio de 2003. Guia de validação de métodos analíticos e bioanalíticos. Diário Oficial da União da República Federativa do Brasil, 02 de junho. Brasília, DF, Brazil: Agência Nacional de Vigilância Sanitária

Aznar O, Checa A, Oliver R, Hernández-Cassou S, Saurina J (2011) Determination of polyphenols in wines by liquid chromatography with UV spectrophotometric detection. J Sep Sci 34:527-535. doi:10.1002/jssc.201000816

Baptista JAB, Tavares JF, Carvalho RCB (2001) Comparison of polyphenols and aroma in red wines from Portuguese mainland versus Azores Islands. Food Res Int 34:345-355. doi:10.1016/ S0963-9969(00)00174-5

Baur JA, Pearson KJ, Price NL, Jamieson HA, Lerin C, Kalra A, Prabhu VV, Allard JS, Lopez-Lluch G, Lewis K, Pistell PJ, Poosala S, Becker KG, Boss O, Gwinn D, Wang M, Ramaswamy S, Fishbein KW, Spencer RG, Lakatta EG, Le Couteur D, Shaw RJ, Navas P, Puigserver P, Ingram DK, Cabo R, Sinclair DA (2006) Resveratrol improves health and survival of mice on a high-calorie diet. Nature 444(7117):337-342. doi:10.1038/ nature 05354

Bidlack WR, Wang W (2006) Phytochemicals. In: Shils ME, Shike M, Ross AC, Caballero B, Cousins RJ (eds) Modern nutrition in health and disease, 10th edn. Lippincott Williams \& Williams, Philadelphia

Bliesner DM (2006) Validating chromatographic methods: a practical guide. Wiley, New Jersey

Burns J, Mullen W, Landrault N, Teissedre P, Lean MEJ, Crozier A (2002) Variations in the profile and content of anthocyanins in wines made from cabernet sauvignon and hybrid grapes. J Agric Food Chem 50:4096-4102. doi:10.1021/jf011233s

Carbonell-Bejerano P, Diego M, Martínez-Abaigar J, MartínezZapater JM, Tardáguila J, Núñez-Olivera E (2014) Solar ultraviolet radiation is necessary to enhance grapevine fruit ripening transcriptional and phenolic responses. BMC Plant Biol 14:1-16. doi:10.1186/1471-2229-14-183

Careri M, Corradini C, Elviri L, Nicoletti I, Zagnoni I (2004) Direct HPLC analysis of quercetin and trans-resveratrol in red wine, grape, and winemaking byproducts. J Agric Food Chem 51:5226-5231. doi:10.1021/jf049219d

Castellari M, Sartini E, Fabiani A, Arfelli G, Amati A (2002) Analysis of wine phenolics by high-performance liquid chromatography using a monolithic type column. J Chromatogr A 973:221-227. doi:10.1016/S0021-9673(02)01195-0

Cielecka-Piontek J, Zalewski P, Jelinska A, Garbacki P (2013) UHPLC: the greening face of liquid chromatography. Chromatographia 76:1429-1437. doi:10.1007/s10337-013-2434-6

Cotea VV, Luchian CE, Bilba N, Niculaua M (2012) Mesoporous silica SBA-15, a new adsorbent for bioactive polyphenols from red wine. Anal Chim Acta 732:180-185. doi:10.1016/j.aca.2011. 10.019

Crespy V, Morand C, Manach C, Besson C, Demigne C, Remesy C (1999) Part of quercetin absorbed in the small intestine is conjugated and further secreted in the intestinal lumen. Am J Physiol 277:120-126

Crespy V, Morand C, Manach C, Besson C, Demigne C, Remesy C (2002) Quercetin, but not its glycosides, is absorbed from the rat stomach. J Agric Food Chem 50:618-621. doi:10.1021/ jf010919h

Crozier A, Clofford MN, Ashihara H (2006) Plant secondary metabolites: occurrence, structure and role in the human diet. Blackwell, Oxford

De Rosso M, Tonidandel L, Larcher R, Nicolini G, Ruggeri V, Vedova AD, De Marchi F, Gardiman M, Flamini R (2012) Study of anthocyanic profiles of twenty-one hybrid grape varieties by liquid chromatography and precursor-ion mass spectrometry. Anal Chim Acta 732:120-129. doi:10.1016/j.aca.2011.10.045

FDA, US Food and Drug Administration (1994). Reviewer guidance, validation of chromatographic methods. http://www.fda.gov/ downloads/Drugs/Guidances/UCM134409.pdf. Accessed 20 March 2016

FDA, US Food and Drug Administration (2001). Guidance for industry: bioanalytical method validation. http://www.fda.gov/ downloads/Drugs/GuidanceComplianceRegulatoryInformation/ Guidances/ucm070107.pdf. Accessed 20 March 2016

Flamini R (2003) Mass spectrometry in grape and wine chemistry. Part I: polyphenols. Mass Spectrom Rev 22:218-250. doi:10. 1002/mas. 10052

Flamini R, Mattivi F, Rosso MD, Arapitsas P, Bavaresco L (2013) Advanced knowledge of three important classes of grape phenolics: anthocyanins, stilbenes and flavonols. Int J Mol Sci 14:19651-19669. doi:10.3390/ijms141019651

Fontana AR, Bottini R (2014) High-throughput method based on quick, easy, cheap, effective, rugged and safe followed by liquid chromatography-multi-wavelength detection for the quantification of multiclass polyphenols in wines. J Chromatogr A 1342:44-53. doi:10.1016/j.chroma.2014.03.044

Gómez-Alonso S, Garcia-Romero E, Hermosín-Gutiérrez I (2007) HPLC analysis of diverse grape and wine phenolics using direct 
injection and multidetection by DAD and fluorescence. J Food Compos Anal 20:618-626. doi:10.1016/j.jfca.2007.03.002

González O, Blanco ME, Iriarte G, Bartolomé L, Maguregui MI, Alonso RM (2014) Bioanalytical chromatographic method validation according to current regulations, with a special focus on the non-well defined parameters limit of quantification, robustness and matrix effect. J Chromatogr A 1353:10-27. doi:10.1016/j.chroma.2014.03.077

Gordillo B, Rodríguez-Pulido FJ, Mateus N, Escudero-Gilete ML, González-Miret ML, Heredia FJ, Freitas V (2012) Application of LC-MS and tristimulus colorimetry to assess the ageing aptitude of Syrah wine in the Condado de Huelva DO (Spain), a typical warm climate region. Anal Chim Acta 732:162-171. doi:10. 1016/j.aca.2012.03.051

ISO, International Organisation for Standardisation (2005) ISO/ IEC17025 General requirements for the competence of testing and calibration laboratories. ISO, Geneva

Kazakevich Y, Lobrutto R (2007) HPLC for pharmaceutical scientists. Wiley, New Jersey

Kerem Z, Bravdo B, Shoseyov O, Tugendhaft Y (2004) Rapid liquid chromatography-ultraviolet determination of organic acids and phenolic compounds in red wine and must. J Chromatogr A 1052:211-215. doi:10.1016/j.chroma.2004.08.105

Khan RS, Grigor J, Winger R, Win A (2013) Functional food product development-Opportunities and challenges for food manufacturers. Trends Food Sci Technol 30:27-37

Lima MTR, Waffo-Téguo P, Teissedre PL, Pujolas A, Vercauteren J, Cabanis JC, Mérillon JM (1999) Determination of stilbenes (trans-astringin, cis- and trans-piceid, and cis- and transresveratrol) in Portuguese wines. J Agric Food Chem 47(7):2666-2670. doi:10.1021/jf9900884

López M, Martínez F, Valle CD, Orte C, Miró M (2001) Analysis of phenolic constituents of biological interest in red wines by highperformance liquid chromatography. J Chromatogr A 922:359-363. doi:10.1016/S0021-9673(01)00913-X

Lorrain B, Ky I, Pechamat L, Teissedre P (2013) Evolution of analysis of polyhenols from grapes, wines, and extracts molecules. Molecules 18:1076-1100. doi:10.3390/ molecules18011076

Malovaná S, Montelongo FJG, Péreza JP, Rodríguez-Delgado MA (2001) Optimisation of sample preparation for the determination of trans-resveratrol and other polyphenolic compounds in wines by high performance liquid chromatography. Anal Chim Acta 428:245-253. doi:10.1016/S0003-2670(00)01231-9

Monagas M, Suárez R, Gómez-Cordovés C, Bartolomé B (2005) Simultaneous determination of nonanthocyanin phenolic compounds in red wines by HPLC-DAD/ESI-MS. Am J Enol Vitic 56:139-174

Murota K, Terao J (2003) Antioxidative flavonoid quercetin: implication of its intestinal absorption and metabolism. Arch Biochem Biophys 417:12-17. doi:10.1016/S0003-9861(03)00284-4

OIV, International Organization of Vine and Wine (2015). HPLCdetermination of nine major anthocyanins in red and rosé wine. In: OIV, Compendium of international methods of analysis. Paris

Paulo L, Domingues F, Queiroz JA, Gallardo E (2011) Development and validation of an analytical method for the determination of trans- and cis-resveratrol in wine: analysis of its contents in 186 Portuguese Red Wines. J Agric Food Chem 59:2157-2168. doi:10.1021/jf105004y

Pereira V, Câmara JS, Cacho J, Marques JC (2010) HPLC-DAD methodology for the quantification of organic acids, furans and polyphenols by direct injection of wine samples. J Sep Sci 33:1204-1215. doi:10.1002/jssc.200900784

Pérez-Magarino S, Ortega-Heras M, Cano-Mozo E (2008) Optimization of a solid-phase extraction method using copolymer sorbents for isolation of phenolic compounds in red wines and quantification by HPLC. J Agric Food Chem 56:11560-11570. doi:10. 1021/jf802100j

Prior RL (2006) Phytochemicals. In: Shils ME, Shike M, Ross AC, Caballero B, Cousins RJ (eds) Modern nutrition in health and disease, 10th edn. Lippincott Williams \& Williams, Philadelphia

Rastija V, Srečnik G, Medić-Šarić M (2009) Polyphenolic composition of Croatian wines with different geographical origins. Food Chem 115(1):54-60. doi:10.1016/j.foodchem.2008.11.071

Renaud S, De Lorgeril M (1992) Wine, alcohol, platelets, and the French paradox for coronary heart disease. Lancet 339:1523-1526. doi:10.1016/0140-6736(92)91277-F

Revilla E, Ryan JM (2000) Analysis of several phenolic compounds with potential antioxidant properties in grape extracts and wines by high-performance liquid chromatography-photodiode array detection without sample preparation. J Chromatogr A 881(1-2):461-469. doi:10.1016/S0021-9673(00)00269-7

Ribéreau-Gayon P, Glories Y, Maujean A, Dubordieu D (2006) Handbook of enology: the chemistry of wine stabilization and treatments, 2nd edn. Wiley, Paris

Rodríguez-Delgado M, González-Hernández G, Conde-González J, Pérez-Trujillo J (2002) Principal component analysis of the polyphenol content in young red wines. Food Chem 78:523-532. doi:10.1016/S0308-8146(02)00206-6

Shabir AG (2003) Validation of high-performance liquid chromatography methods for pharmaceutical analysis. Understanding the differences and similarities between validation requirements of the US Food and Drug Administration, the US Pharmacopeia and the International Conference on Harmonization. J Chromatogr A 987:57-66. doi:10.1016/S0021-9673(02)01536-4

Silva CL, Pereira J, Woutera VG, Giróa C, Câmara JS (2011) A fast method using a new hydrophilic-lipophilic balanced sorbent in combination with ultra-high performance liquid chromatography for quantification of significant bioactive metabolites in wines. Talanta 86:82-90. doi:10.1016/j.talanta.2011.08.007

Tenore GC, Troisi J, Di Fiore R, Manfra M, Novellino E (2011) Nutraceutical value and toxicological profile of selected red wines from Morocco. Food Chem 129:792-798. doi:10.1016/j. foodchem.2011.05.022

Tringali C (2012) Bioactive compounds from natural sources. CRC Press, New York

Villiers A, Lynen F, Crouch A, Sandra P (2004) Development of a solid-phase extraction procedure for the simultaneous determination of polyphenols, organic acids and sugars in wine. Chromatographia 59:403-409. doi:10.1365/s10337-004-0204-1

Vitrac X, Bornet AL, Vanderlinde R, Valls J, Richard T, Delaunay JC, Rillon JMM, Teisseädre PL (2005) Determination of stilbenes $(\delta$-viniferin, trans-astringin, trans-piceid, cis-and trans-resveratrol, $\varepsilon$-viniferin) in Brazilian wines. J Agric Food Chem 53:5664-5669. doi:10.1021/jf050122g

Vrhovsek U, Masuero D, Gasperotti M, Franceschi P, Caputi L, Viola R, Mattivi F (2012) A versatile targeted metabolomics method for the rapid quantification of multiple classes of phenolics in fruits and beverages. J Agric Food Chem 60(36):8831-8840. doi:10.1021/jf2051569

Wu Q, Wang M, Simon JE (2005) Determination of proanthocyanidins in fresh grapes and grape products using liquid chromatography with mass spectrometric detection. Rapid Commun Mass Spectrom 19:2062-2068. doi:10.1002/rcm.2029

Zhou J, Cui H, Wan G, Xu H, Pang Y, Duan C (2004) Direct analysis of trans-resveratrol in red wine by high performance liquid chromatography with chemiluminescent detection. Food Chem 88:613-620. doi:10.1016/j.foodchem.2004.05.003 